\title{
ПЕРСПЕКТИВЫ ИСПОЛЬЗОВАНИЯ РОБОТИЗИРОВАННОГО ДОЕНИЯ В МАЛЫХ ФОРМАХ ХОЗЯЙСТВОВАНИЯ
}

\author{
КОМЛАЦКИЙ Григорий Васильевич, Кубанский государственный аграрный университет \\ имени И.Т. Трубилина
}

МЕЛЬНИЧЕНКО Антон Александрович, Кубанский государственный аграрный университет имени И.Т. Трубилина

ЛАЗАРЕВ Дмитрий Олегович, $K(\Phi) X$ «БоровеИ Е.Е.»

В условиях крестъянского (фермерского) хозяйства проведен научно-производственный опыт, иелью которого было определение молочной продуктивности коров голитинской породы датской селекции при использовании робота-дояра. Установлено, что удой коров первой лактации находился в пределах 8237 кг. С учетом того, что в последующие лактации молочная продуктивность возрастает, можно сделать вывод, что инновационная технология роботизированного доения в условиях семейной фермы позволяет в полной мере реализовать генетический потенциал животных. Полученные данные корреспондируются с результатами других исследователей, что подтверждает их достоверность. Адаптация животных к роботизированному доению происходила в течение месяца, при этом наблюдения за поведением коров показали, что из 40 коров 18 животных добровольно посещали робота дояра 2 раза в течение суток. У 22 голов из 40 количество посещений было равно 3. Лищъ 2 коровы из всей группы заходили на дойку всего 1 раз за сутки. По наблюдениям за продолжительностью сеанса доения установлено, что время посещений коровами робота дояра варьировало в среднем от 3 до 15 мин. При этом на интервал 5-7 мин приходится более половины всех посещений. Посещения встречаются как укороченные (менее 5 мин), так и удлиненные (10 мин и дольше). Бережная обработка вымени и установка доильных стаканов обеспечивают не только хорочее состояние вымени, но и влияют на улучшение качества молока. Технология, основанная на самообслуживании, дает животным право выбора сроков и частоты посещений роботизированной станции доения, существенно снижает стрессовую ситуацию и повышает продуктивность и качество молока. Полученные данные подтверждают иелесообразность использования высокотехнологичной схемы доения молока в семейных фермах и других малых формах хозяйствования.

Введение. Одной из самых трудоемких и ответственных операций в молочном скотоводстве является доение [3]. Актуальность и значимость проблемы послужили поводом для создания автоматизированных устройств и оборудования для молочного скотоводства. Еще 50-60 лет назад начались разработки и испытания устройств - прообразов сегодняшних роботов. В результате в конце XX века появились роботы-дояры [10]. Первый из них Astronaut был выпущен голландской фирмой Lely, которой принадлежит более половины выпускаемых в мире устройств. Хотя количество производителей роботизированного оборудования для доения коров в мире не слишком велико, между ними существует довольно высокая конкуренция. В России более десяти лет назад началось достаточно робкое, но перспективное внедрение современного оборудования для роботизированного доения. Лидером по объему установленных роботов является компания DeLaval, Швеция. На долю оборудования этой фирмы приходится около 25-30 \% мирового рынка доильной робототехники. Большой практический опыт использования доильных роботов накоплен в Курской и Калужской областях [7]. Есть примеры успешного использования роботизированной доильной техники в Вологодской об- ласти [5]. Повсеместное распространение роботов в российском животноводстве сдерживается их высокой ценой и повышенными энергозатратами, а также рядом опасений из-за неподготовленности кадров для эксплуатации и сервиса установок.

Целью исследований явилась оценка перспектив использования роботизированного оборудования для доения в малых формах хозяйствования.

Методика исследований. В условиях крестьянского (фермерского) хозяйства был проведен научно-хозяйственный опыт по определению поведения и молочной продуктивности коров импортной селекции при использовании робота-дояра. Проведен сопоставительный анализ полученных данных с генетически заложенными показателями. Объектом исследований послужили коровы голштинской породы датской селекции в количестве 68 голов с выменем правильной чашеобразной формы и размеров.

Продуктивность коров учитывали по данным проводимых контрольных доений. Молочную продуктивность (удой за 305 дней лактации; среднее содержание белка, жира в молоке) изучали на коровах-первотелках на основе показателей доильного оборудования. 
Наблюдение за поведением животных осуществляли с помощью системы управления стадом «Delpro» (среднее количество доек за сутки, среднее количество проходов через селекционные ворота за сутки). Основные результаты исследований были обработаны биометрически (Плохинский Н.А.).

Результаты исследований. Роботизированная технология предусматривает беспривязное содержание коров и доение посредством робота-дояра. Отличительной особенностью технологии является то, что животные сами решают, когда нужно их доить, и добровольно подходят к роботизированной установке. Таким образом, сбор молока происходит в спокойной, бесстрессовой обстановке. Это улучшает его качество и положительно сказывается на состоянии коровы, особенно на состоянии вымени. При вхождении коровы в доильную станцию робот определяет положение вымени, производит его обработку (обмывание, массаж и установку доильных стаканов) и осуществляет отбор молока. При этом гидравлическая рука работает бережно и тихо. Место постоянного пребывания коров разделено на секторы для кормления, отдыха и доения. Между ними установлены интеллектуальные ворота. Специальный сенсор сканирует с них информацию, и если животному пора доиться, направляет его к роботу, а если нет, то в зону отдыха. В следующий раз корова может подойти к роботу только через определенное время, автоматически определяемое в зависимости от уровня молочной продуктивности.

Отбор молока или собственно доение осуществляется индивидуально для каждой четверти вымени. Система оснащена отдельными счетчиками молока для каждой четверти для регистрации времени, количества надоя, интенсивности, электропроводности и наличие крови в молоке. Управляющее программное обеспечение систе- мы представляет доступ к информации каждой коровы, что позволяет своевременно принять правильное решение по ветеринарно-санитарному обслуживанию животных.

Для того чтобы коровы добровольно заходили на доильную станцию, в кормушку кладут корм, более вкусный, чем животные получают на кормовом столе. Максимальная дача концентратов составляет 0,75 кг на посещение. Минимальное количество получают коровы с низкой продуктивностью, которые доятся дважды в день. В остальное время коровы имеют свободный доступ к кормам, которые подвозятся мобильным транспортом на кормовой стол. В зоне кормления утром все животные получают усредненное количество корма исходя из 25 кг однотипного рациона на период лактации. После доения порция корма зависит от количества сданного молока от каждой коровы. Для всех животных обеспечен постоянный доступ к воде.

Робот-дояр компании DelavaI с гидравлическим приводом, входящий в состав системы VMS, обладает высокой надежностью. Система визуализации сосков имеет оптическую камеру, объединенную с двумя лазерами, которые обеспечивают быстрое и надежное подсоединение доильных стаканов. Механическая рука последовательно находит и обмывает водой вымя, прикрепляет и после выдаивания снимает доильные стаканы. Компьютер считывает информацию о корове и отображает на мониторе сведения о количестве и качестве молока. По окончании доения открываются ворота, корова выходит, а ее место занимает другая.

Животные содержатся в коровнике, в котором установлена система добровольного доения, а также имеются зона для отдыха (боксы), станция кормления, операторская, молочный блок с танком-охладителем. Коровы свободно передвигаются по корпусу, едят и сами по очереди

Таблица 1

Молочная продуктивность подопытных коров, $\boldsymbol{n}=40$

\begin{tabular}{|c|c|c|c|}
\hline Показатель & $M \pm m$ & $\delta$ & $\mathrm{Cv}$ \\
\hline Удой за 305 дней лактации, кг & $8237 \pm 16,6$ & 104,4 & 1,3 \\
\hline Средняя жирность молока, \% & $4,2 \pm 0,02$ & 0,12 & 2,8 \\
\hline Средняя белковость молока, \% & $3,1 \pm 0,02$ & 0,13 & 4,1 \\
\hline Количество молочного жира за лактацию, кг & $345,9 \pm 5,9$ & 37,4 & 10,8 \\
\hline Количество молочного белка за лактацию, кг & $257,0 \pm 3,8$ & 24,0 & 9,3 \\
\hline Средняя живая масса коров, кг & $531 \pm 19$ & 40,2 & 7,8 \\
\hline
\end{tabular}


проходят через «интеллектуальные ворота». Молочную продуктивность подопытных животных учитывали за 305 дней лактации. Показатели молочной продуктивности представлены в табл. 1.

Данные табл. 1 показывают, что за 305 дней удой составил 8237 кг, средняя жирность молока была в пределах $4,2 \%$, количество белка в нем $3,1 \%$.

Наблюдения за поведением коров показали, что из 40 голов коров 18 голов добровольно посещали робота дояра 2 раза в течение суток. У 22 голов из 40 количество посещений было равно 3. Лишь 2 коровы, из всей опытной группы, заходили на дойку всего 1 раз за сутки.

Нами была изучена продолжительность сеанса доения коров роботом-дояром. Установлено, что время посещений коровами робота дояра варьировало в среднем от 3 до 15 мин. При этом на интервал 5-7 мин приходится 51 \% всех посещений; 7-12 мин - 49\%. Посещения встречаются как укороченные (менее 5 мин), так и удлиненные (10 мин и дольше). Основная причина - длительный поиск сосков вымени доильным манипулятором, что является недостатком конструкции используемых роботов-дояров. Однако данную проблему можно решить, наладив доильный манипулятор на поиск сосков коровы.

В связи с разным поведением коров перед доением, в период и после него, стадо животных нами было условно разделено на три группы. Животные с активным агрессивным типом поведения расталкивали других коров, первыми оказывались у места доения. После окончания доения начинали стучать лбом по станции. Коровы с активным уравновешенным типом поведения вели себя активно, но без агрессии. К третьему, слабовыраженному типу можно отнести пассивных животных. Проведенные наблюдения за типом поведения анализируемых групп животных перед доением представлены в табл. 2.

В результате проведенных наблюдений установлено, что в опытной группе коров слабовыраженный тип поведения отсутствовал. Основу группу составили животные с активным уравновешенным типом поведения - 82,5 \% (33 головы). Они активно поедают корм и посещают доильную установку и, как следствие, демонстрируют высокую молочную продуктивность.

В результате использования технологии роботизированного доения рентабельность производства молока в К $(\Phi)$ Х составила $46,5 \%$.

Заключение. Инновационная технология доения, основанная на самообслуживании и мотивации животного пройти через робота-дояра, в условиях семейной фермы позволяет в полной мере реализовать генетический потенциал животных. Важным достоинством использования робота является исключение человеческого фактора, что обеспечивает постоянство процесса доения. Выполнение роботом одних и тех же операций в строго запланированном порядке уменьшает стрессовую нагрузку на животных. Использование робота обеспечивает интеграцию действий средств автоматизации с процессом лактации животного. Управление технологическим процессом становится более информативным, позволяющим отслеживать на блоке управления динамику каждого животного по надоям, состоянию вымени и поведению. Применение технологии бережливого содержания и ухода за животными продлевает срок их продуктивного использования и повышает производительность труда. Полученные данные подтверждают целесообразность использование высокотехнологичной схемы доения молока в семейных фермах и других малых формах хозяйствования.

\section{СПИСОК ЛИТЕРАТУРЫ}

1. Винницки С., Юговар Е., Артс И. Эффективность применения доильного робота на семейных фермах // Вестник Марийского государственного университета. - 2014. - №1(13). - С. 68-72.

2. Горелик О.В. Федосова Н.А., Киселев Л.Ю. Частота доения - путь к увеличению молочной продуктивности в условиях роботизированной фермы // Аграрный вестник Урала. - 2018. - № 11(178). - С. 27-31.

3. Комлаикий В.И., Куликова Н.И., Щукина И.В. Технология производства говядины. - Ростов н/Д., 2015. - 347 c.

4. Ляшенко В.В., Ситникова И.В. Продуктивность голштинских коров-первотелок разной селекции // Нива Поволжья. - 2014. - № 3(32). - С. 17-19.

5. Маклахов А.В., Жильцов В.И., НикитинЛ.А.Сравнительная оценка экономической эффективности использования доильных роботов в ООО»Покровское» Вологодской области // Вопросы территориального развития. - 2017. - № 5(40). - С. 1-15.

6. Морозова Н.И., Мусаева Ф.А., Садиков Р.З. Молочная продуктивность голштинских коров в ус-

Таблица 2

Тип поведения коров-первотелок, подопытных групп, перед доением

\begin{tabular}{|l|c|c|}
\hline \multicolumn{1}{|c|}{ Тип поведения } & Голов & $\%$ \\
\hline Активный агрессивный & 7 & 17,5 \\
\hline Активный уравновешенный & 33 & 82,5 \\
\hline Слабовыраженный & - & - \\
\hline Всего & 40 & 100 \\
\hline
\end{tabular}


ловиях роботизированного комплекса // Вестник РГВТУ. - 2018. - № 2(38). - С. 32-36.

7. Тихомиров И.И., Скоркин В.К. Опыт использования доильных роботов в молочном скотоводстве на примере хозяйств Калужской области // Вестник ВНИИМЖ. - 2019. - № 1(83). - С. 160-166.

8. Тяпугин Е.А., Тяпугин С.Е., Углин В.К. Особенности роботизированной технологии доения высокопродуктивных коров на современных комплексах // Достижения науки и техники АПК. 2015. - T. 29. - № 2. - С. 57-58.

9. Улимбашев М.Б. Пригодность вымени коров бурой швицкой породык роботизированной технологии доения // Сельскохозяйственный журнал. 2019. - № 2(19). - С. 58-65.

10. Цой Ю.А., Бакщева Р.А. Тенденции развития роботизированного доения // Вестник ВНИИМЖ. 2019. - № 3(35). - С. 73-82.

11. Чеченихина О.С. Эффективность внедрения роботизированной системы доения крупного рогатого скота // Аграрный вестник Урала. - 2018. № 08(175). - С. 62-69.
12. Шарипов Д.Р., Ахметов Т.М., Равилов Р.Х. Способ отбора коров для роботизированного доения // Патент РФ № 2723181 от 07.02.2020, МПК А0167/02

13. Шевхужев А.Ф. Современные технологии производства молока с использованием генофонда голштинского скота. - М., 2015. - 392 с.

Комлацкий Григорий Васильевич, $\partial-p$ c.-x. наук, проф. кафедры «Институциональная экономика и инвестиционный менеджмент», Кубанский государственный аграрный университет имени И.Т. Трубилина. Россия.

Мельниченко Антон Александрович, магистр зоотехнии, Кубанский государственный аграрный университет имени И.Т. Трубилина. Россия.

Лазарев Дмитрий Олегович, $K(\Phi) X$ «Боровеи Е.Е.». Россия.

350004, г. Краснодар, ул. Калинина, 21.

Тел.: (918) 448-73-64.

Ключевые слова: молочная продуктивность; голштинская порода; роботизированное доение; лактация; поведение коров; адаптация; семейная ферма; малые формы хозяйствования.

\section{PROSPECTS FOR THE USE OF ROBOTIC MILKING IN SMALL ECONOMIES}

Komlatsky Grigory Vasilievich, Doctor of Agricultural Sciences, Professor of the chair "Institutional Economy and Investment Management”, Kuban State Agrarian University named after I.T. Trubilin. Russia.

Mlnichenko Anton Aleksandrovich, Master of Animal Sciences, Kuban State Agrarian University named after I.T. Trubilin. Russia.

Lazarev Dmitry Olegovich, Peasant farm "Borovets E.E.". Russia.

Keywords: milk production; Holstein breed; robotic milking; lactation; cow behavior; adaptation; family farm; small forms of farming.

In the conditions of a peasant farm, a research and production experiment was carried out, the purpose of which was to determine the milk productivity of Holstein cows of Danish selection using a robot milker. It was found that the milk yield of the first lactation cows was within $8237 \mathrm{~kg}$. Taking into account the fact that milk productivity increases in subsequent lactations, it can be concluded that the innovative technology of robotic milking in a family farm allows the genetic potential of animals to be fully realized. The data obtained are consistent with the results of other researchers, which confirms their reliability. The adaptation of animals to robotic milking took place within a month, while the observations of the behavior of cows showed that out of 40 cows, 18 animals voluntarily visited the robotic milker 2 times a day. 22 out of 40 cows had 3 visits. Only 2 cows from the whole group went to milking only once a day. According to the observations of the duration of the milking session, it was found that the time spent by the cows visiting the robotic milker varied on average from 3 to 15 minutes. Moreover, the interval of 5-7 minutes accounts for more than half of all visits. Visits are both shorter (less than 5 minutes) and extended (10 minutes or more). Gentle udder treatment and placement of teat cups not only ensure good udder health, but also improve milk quality. Self-service technology gives animals the right to choose the timing and frequency of visits to the robotic milking station, significantly reduces the stress situation and increases the productivity and quality of milk. The data obtained confirm the feasibility of using a high-tech milk milking scheme in family farms and other small forms of farming. 